\title{
Microglia, major player in the brain inflammation: their roles in the pathogenesis of Parkinson's disease
}

\author{
Yoon Seong Kim* and Tong H. Joh \\ Department of Neurology and Neuroscience \\ Weill Medical College of Cornell University \\ New York, NY 10021, USA \\ *Corresponding author: Tel, 212-746-4505; \\ Fax, 212-746-8276; E-mail, yok2001@med.cornell.edu
}

Abbreviations: $A \beta$, amyloid beta; $A D$, Alzheimer's disease; $\alpha-\mathrm{MSH}$, alpha-melanocyte stimulating hormone; BBB, blood brain barrier; COX-2, cyclooxygenase-2; IL-1Ra, IL-1 receptor antagonist; iNOS, inducible nitric oxide synthase; LBP, LPSbinding protein; MMP-3, matrix metalloproteinase-3; MPTP, 1-methyl-4-phenyl-1,2,3,6-tetrahydropyridine; MS, multiple sclerosis; NADPHO, NADPH oxidase; NFTs, neurofibrillary tangles; $\mathrm{NF}-\kappa \mathrm{B}$, nuclear factor $\kappa \mathrm{B}$; NO, nitric oxide; PD, Parkinson's disease; RAGE, receptors for advanced glycosylated endproducts; SN, substantia nigra; TIr4, toll-like receptor 4; tPA, tissue plasminogen activator; VIP, vasoactive intestinal peptide

\begin{abstract}
Inflammation, a self-defensive reaction against various pathogenic stimuli, may become harmful self-damaging process. Increasing evidence has linked chronic inflammation to a number of neurodegenerative disorders including Alzheimer's disease (AD), Parkinson's disease (PD), and multiple sclerosis. In the central nervous system, microglia, the resident innate immune cells play major role in the inflammatory process. Although they form the first line of defense for the neural parenchyma, uncontrolled activation of microglia may directly toxic to neurons by releasing various substances such as inflammatory cytokines (IL-1 $\beta$, TNF- $\alpha$, IL-6), $\mathrm{NO}, \mathrm{PGE}_{2}$, and superoxide. Moreover, our recent study demonstrated that activated microglia phagocytose not only damaged cell debris but also neighboring intact cells. It further supports their active participation in self-perpetuating neuronal damaging cycles. In the following review, we discuss microglial responses to damaging neurons, known activators released from injured neurons and how microglia cause neuronal degeneration. In the last part, microglial activation and their role in PD are discussed in depth.
\end{abstract}

Keywords: inflammation; microglia; neurodegenerative diseases; Parkinson's disease; phagocytosis; stromelysin 1; superoxides

\section{Introduction}

Inflammation is the first response of our body's immune system to pathogens or irritation. Inflammation is a two-edged sword. In acute conditions, it protects tissue against invading agents and promotes healing. On the other hands, when chronically sustained, it can cause serious damage to host's own tissue. While the CNS has been known as an immune privileged organ, increasing evidence demonstrate that inflammation is actively involved in pathogenesis of a number of neurodegenerative diseases including multiple sclerosis (MS), Alzheimer's disease (AD), Parkinson's disease (PD), and HIV-associated dementia (Raine, 1994; Banati et al., 1998; McGeer et al., 1988). Chronic inflammation-mediated tissue damage can be particularly harmful to the brain, since neurons are generally irreplaceable. Microglia, antigen presenting brain immune cells (or macrophages), are the innate immune components in the CNS parenchyma. Under normal condition, they may sentinel the CNS parenchymal integrity. Activated microglia at the site of inflammation change their morphology, express increased levels of MHC antigens and become phagocytic (Hayes et al., 1987; 1988). They release inflammatory cytokines that amplify the inflammatory response by activating and recruiting other cells to the brain lesion. In addition, microglia can release potent neurotoxins, which may cause neuronal damage. Sustained overactivation of microglia has been observed in multiple neurodegenerative diseases. In the following review, we mainly discuss the microglial activation and its implication in the pathogenesis of PD.

\section{Unique immune properties of the central nervous system}

Antigen presentation is an important process in the immune system which links innate immunity to adaptive immunity. This process involves APCs capable of engulfing foreign pathogens, processing and presenting antigen in the MHC molecules on the cell surface. Antigens on the surface of APCs are recognized either by CD4 or by CD8 T cells and they become fully activated only when receiving additional co-stimulatory signals from APCs. While most peripheral tissues are supported by immune surveillance coordinated by T cells and APCs such as 
macrophage and dendritic cells (professional APCs) or B cells and certain stromal cells (non-professional APCs) (Mellman and Steinman, 2001), such sentinels seem limited in the CNS. In fact, allografts were demonstrated to survive longer than those on other tissues (Barker and Billingham, 1977). The blood brain barrier (BBB) consisting of endothelial tight junction, parenchymal basement membrane and glial limitans of astrocytes, restricts the passage of plasma proteins and the immune components such as lymphocytes, antibodies and complements. Furthermore, the CNS was thought to lack of conventional lymphatic drainage. It was reported that a number of anti-inflammatory substances such as TGF- $\beta$, Fas ligand and ganglioside, which inactivate or kill immune cells (Becher et al., 1998; Benveniste, 1998; Irani, 1998; Bechmann et al., 1999; Gozes et al., 1999; Pender and Rist, 2001; Vitkovic et al., 2001). Increasing reports, however, demonstrate that some degree of immune surveillance of the CNS exists and is crucial to prevent disease development. For instance, some latent viruses such as JC virus or varicella zoster produce clinical syndromes mainly in immuno-compromised individuals. MHC and co-stimulatory molecules are strongly increased in CNS infection and a number of CNS pathologic conditions, including ischemia, neoplasm, traumatic nerve injury and neurodegenerative diseases such as AD, PD, MS, HIV-dementia and Creutzfeldt-Jacob disease (Maehlen et al., 1989; McGeer et al., 1993; An et al., 1996; Graeber et al., 1998; Perry, 1998; Dorries, 2001; Piehl and Lidman, 2001; O'Keefe et al., 2002; Owens, 2002). Recent evidence has implied that the CNS equips itself with a unique defense system with its own molecular and cellular components despite sharing certain properties with the peripheral immune system.

Cellular components involved in the inflammatory response associated with neurodegeneration comprise mainly two parts according to their location: resident cell types in the parenchyma such as astroglia and microglia; CNS-associated cells, phagocytes characterized as macrophages and dendritic cells based on molecular and functional phenotype. They have been recently identified in compartments associated with the CNS, such as the Virchow-Robin (perivascular) space, the leptomeninges, and the choroids plexus (McMenamin, 1999; Serafini et al., 2000; Fischer and Reichmann, 2001; Williams et al., 2001). CNS-associated cells are continuously replenished by bone-marrow derived cells (Hickey et al., 1992; Bechmann et al., 2001). Under various pathologic conditions of the CNS, they are activated and increase numbers. They constitutively express high levels of MHC II, CD11b, co-stimulatory molecules and leukocyte common antigen CD45
(CD45 $\left.5^{\text {high }}\right)$. In contrast, the levels of CD45 of parenchymal microglia are relatively low $\left(C D 45^{\text {low }}\right)$. Isolated these CD45 $5^{\text {high }}$ CNS-associated cells showed to activate both naïve and primed CD4 T cells even more efficiently than CD45 ${ }^{\text {low }}$ microglia isolated from the same animals (Ford et al., 1996; Carson et al., 1998; 1999).

\section{Microglia: the immune component in the CNS parenchyma}

The initial definitive investigation of microglia was carried out by del Rio-Hortega early in the $20^{\text {th }}$ century. His intensive research described microglia as a distinct cell type in the central nervous system with extensively branched morphology and close contact with neurons and astrocytes. He also showed that the cells changed their morphology dramatically upon severe brain injuries such as stab wounds and that they migrated to the lesion site, proliferated and phagocytosed dying cells and other debris (del Rio-Hortega, 1932). Microglia comprise about $10 \%$ of the total glial population in the CNS parenchyma (Perry, 1998). Regarding the origin of microglia, the most widely accepted hypothesis is that they migrate from yolk sac to the CNS and differentiated into microglia (Alliot et al., 1999). Microglia, however, are not readily differentiated from bone marrow-derived monocytes during adulthood, suggesting they derive from different monocytic leanage (Hickey et al., 1992; Becher et al., 2003). Microglia are important to the normal development of the embryo. Overproduced neurons destined to die by programmed cell death are thought to be removed by microglia that display an immature, nonramified morphology. After the completion of the CNS sculpting, microglia fully differentiate into a ramified resting state. The function of resting microglia has not been fully elucidated, but they may release low levels of growth factors that support the survival of neurons and glia. Recent in vivo imaging studies demonstrate that microglia actively monitor the CNS parenchymal environment by continual movement of their fine processes in the healthy brain (Nimmerjahn et al., 2005). In the mouse brain cortex, microglial processes and protrusions directly contact to astrycytes, neuronal cell bodies and blood vessel, suggesting close communication each others (Nimmerjahn et al., 2005). Upon focal stresses, microglial processes extend toward the injured sites and shield the injured area from the healthy tissue. It is also suggested that ATP released from the damaged neurons or astrocytes regulates microglial process dynamics and rapid response towards injury (Davalos et al., 2005). 
These results indicate that they form the first line of defense against brain damage and play a role in maintaining the microenvironmental homeostasis by removing dead cells and microbes and by supporting damaged neurons. However, by excessive releasing of substances which may be dangerous to cells, microglia might contribute to neurologic disorders (Streit and Kincaid-Colton, 1995). Overall the effect of microglia may depend on both pathologic conditions and severity of injuries.

\section{Neuronal control of microglial quiescence under normal conditions}

Recent studies have showed that neurons suppress microglial activation in coordinate with astrocytes under normal physiologic conditions of the CNS. A glycoprotein, CD200 expressed on the surface of neurons, keeps microglia quiescence by engagement with its receptor on microglia (Hoek et al., 2000). In CD200 knock out mice, microglia were spontaneously activated as determined by increased CD11b and CD45 as well as by loss of their ramified morphology (Hoek et al., 2000). Electrical activity and soluble factors released from intact neurons also maintain microglial quiescence. In neuron-glia co-culture, blockade of neuronal electrical activity by tetrodotoxin or glutamate receptor antagonist facilitated microglial activation induced by IFN- $\gamma$ (Neumann, 2001). The soluble molecules from neurons including neurotransmitters and trophic factors also led to suppression of MHC II and co-stimulatory molecules for antigen presentation (Wei and Jonakait, 1999; Neumann, 2001). Interestingly, astrocytes are able to suppress microglial activation by releasing TGF- $\beta$ or IL-10 (Vincent et al., 1997; Aloisi, 2001) (Figure 1). Taken together, under normal physiologic conditions, microglia are maintained quiescence by coordinate action of neurons and astrocytes. When integrity of the CNS parenchyma is disrupted, microglia are rapidly activated, probably as results of both loss of inhibition by neurons or direct activation signal from neurons (Figure 2). The signals involved in microglial activation will be discussed in detail later.

\section{Antigen presentation by Microglia}

Microglia are the only resident cells in the CNS that have the capability to mediate immune responses. Their antigen presentation in vivo has been demonstrated both in the normal brain and inflammatory conditions caused by LPS injection, neuronal damage or MS lesions (Andersson et al., 1992; Shrikant and Benveniste, 1996; Krogsgaard et al., 2000). To fully activate T-cells, microglia are required to express HLA/MHC with members of the B7 and/or CD40 families, the co-stimulatory molecules. The expression of B7-1, B7-2, B7-3 and CD40 mRNA are shown in rat microglia, and are upregulated by GM-CSF. Cytokines and growth factormediated regulation of these molecules have been demonstrated. A MHC class II molecule is important to antigen presentation. The expression of this molecule in microglia can be regulated by a variety of agents. IFN- $\gamma$ is a potent stimulant of MHC class II antigens (Pazmany et al., 2000). Upregualtion of MHC class II, CD40 and ICAM- 1 by IFN- $\gamma$ triggers $\mathrm{T}$-cell proliferation and production of IL-2 and IFN- $\gamma$ by Th1 and IL-4 by Th2 cells (Aloisi et al., 1998). Several molecules including PGE2, neurotrophins, IL-10 and TGF- $\beta 1$ have also been reported as suppressors of MHC class II antigens (Suzumura et al., 1993; Levi et al., 1998; Neumann et al., 1998; Broderick et al., 2000). This body of evidence delineates microglia as the specific cells which have the capacity for professional antigen presentation.

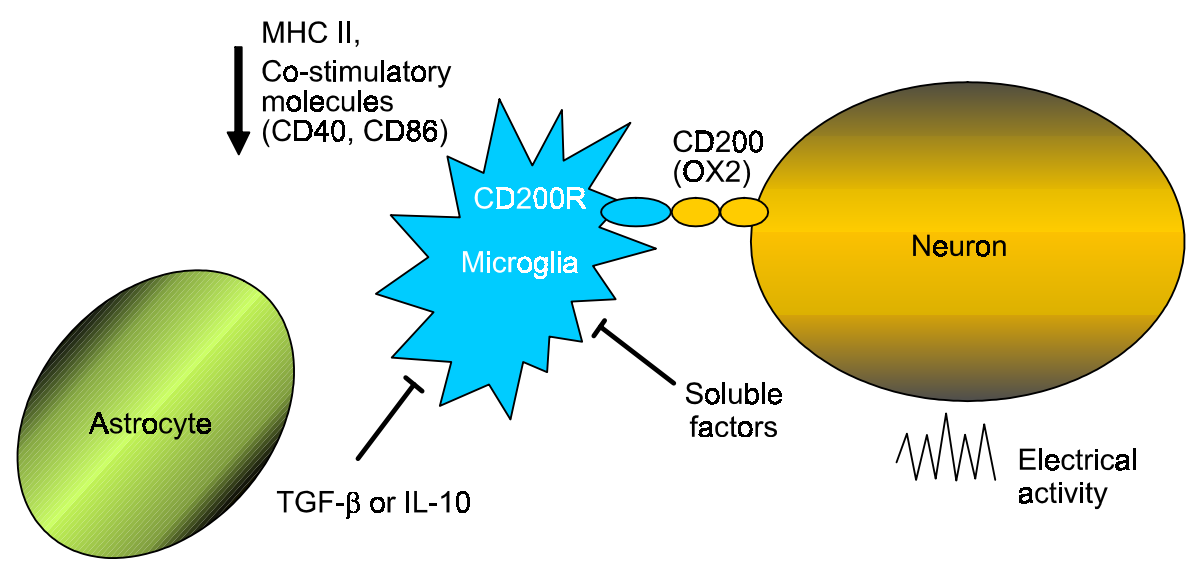

Figure 1. Maintenance of microglial quiescence under normal physiologic condition of the CNS. Microglia are suppressed by neurons or astrocytes under normal condition. Microglial activation is inhibited by the engagement of CD200, glycoprotein expressed on the surface of neurons and its receptor on microglia. Normal electric activity and soluble factors released from neurons (neurotransmitters and neurotrophic factors) also suppress microglial $\mathrm{MHC}$ II and co-stimulatory factors such as CD40 and CD86. TGF- $\beta$ and IL-10 secreted from astrocytes also inhibit microglial activation. 

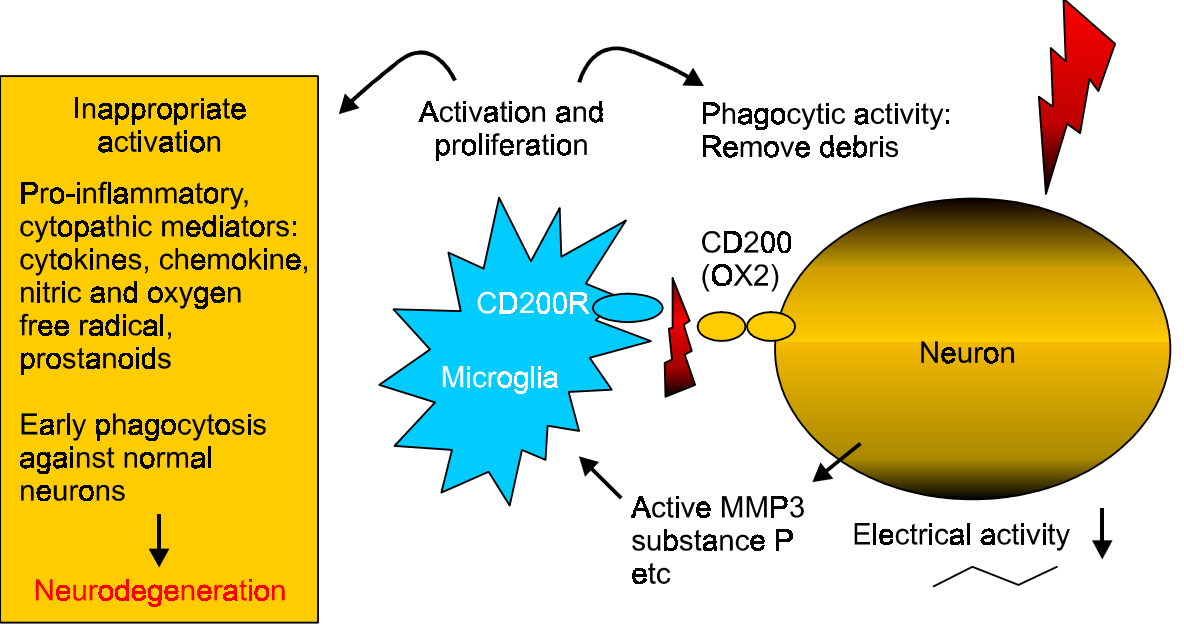

Figure 2. Microglial activation upon neuronal damage. When neurons are injured, microglia are rapidly activated as a result of both a weakening neuronal inhibitory signals and activating stimulatory signals. Loss of neuronal integrity results in breakdown of microglial inhibitory molecules such as CD200, soluble inhibitors. Instead, microglial stimulatory signals including MMP-3 and substance P are rapidly turned on and activate microglia. Activated microglia phagocytose at sites of neuronal damage, and increase in numbers, either from proliferation or recruitment, in order to remove damaged tissue and promote repair. However, their inappropriate activation as in neurodegenerative disorders causes direct damage to the CNS either by releasing potentially toxic substances such as proinflammatory cytokines, chemokines, $\mathrm{NO}$, superoxide and prostanoids or by early phagocytosis against normal neurons.

\section{Antiinflammatory and proinflammatory cytokine release by Microglia}

In the normal CNS, brain tissue provides an immunosuppressive environment, which seems to be important for proper function of the CNS. This immunosuppressive environment is supported by several molecules such as TGF- $\beta, \alpha-M S H$, VIP and FasL, and also by the BBB (Cserr and Knopf, 1992; Perry, 1998; Bechmann et al., 1999; Flugel et al., 2000). Under circumstances that cause the disruption of this environment, such as infectious diseases, autoimmune diseases or chronic inflammatory conditions in neurodegenerative diseases, a variety of immune regulatory and inflammatory mediators can be activated. Cytokines are key regulators of innate and adaptive immune responses. Although various types of cells including tissue infiltrating immune cells, neurons, microglia and astrocytes have been identified as sources of cytokines in the CNS, microglia appear to be a principal source of proinflammatory and immune regulatory cytokines.

$\mathrm{IL}-1$ and TNF- $\alpha$ are two main proinflammatory cytokines produced by microglia during CNS inflammation. Pathogens or pathogen components such as LPS can immediately induce IL- 1 and TNF- $\alpha$ both in cultured microglia and in LPS-injected rats (Appel et al., 1995; Buttini and Boddeke, 1995). IL-1 and TNF- $\alpha$ have been shown to be involved in the development of CNS inflammation through the disruption of the BBB, the induction of adhesion molecules and chemokines from astrocytes and endothelial cells, which facilitate the infiltration of leukocytes into the CNS (Oh et al., 1999; Sedgwick et al., 2000). In addition, recent studies employing TNF- $\alpha$ over-expressing mice demonstrate that TNF$\alpha$ may directly initiate CNS tissue destruction as well as maintain autoimmune inflammation (Taupin et al., 1997; Akassoglou et al., 1998).

Although the studies in the past have focused on microglial production of proinflammatory cytokines, recently, a large body of evidence has supported the notion that microglia also produce cytokines with anti-inflammatory activity, such as TGF- $\beta, \mathrm{IL}-10$, and IL-1 receptor antagonist (IL-1Ra). IL-1Ra counteracts the biological effect of IL-1 by binding to the IL-1 receptor without initiating signal transduction. Both TGF- $\beta$ and IL-10 inhibit microglial activation through their ability to inhibit antigen presentation and proinflammatory cytokines, chemokines and reactive oxygen intermediates (Frei et al., 1994; Aloisi et al., 1999a; O'Keefe et al., 1999). Additionally, microglia can release reactive oxygen intermediates that may cause neuronal damage, express Fas and FasL, which mediate apoptosis of immune cells by microglia and also express growth factors that support neuronal survival.

In summary, a number of studies have demon- 
strated that microglia play an important role in inflammatory conditions in the CNS as a principal source of a variety of inflammatory and immune regulatory mediators.

\section{Molecules involved in microglial activation and signal transduction pathways}

Several molecules, including LPS, IFN- $\gamma, A \beta$, CD40L, chemokines, neurotransmitters and gangliosides, and several proteases such as thrombin, tissue plasminogen activator (tPA) and matrix metalloproteinase-3 (MMP-3) are found to be involved in microglial activation. Some of them are from neurons and others are from pathogens, immune cells or microglia (abd-el-Basset and Fedoroff, 1995; Tsirka, 1997; Suzumura et al., 1998; Tan et al., 1999a; Aloisi et al., 1999b; Moller et al., 2000; Kim et al., 2005).

LPS, an endotoxin from the gram-negative bacterial cell wall, is a potent immunostimulant (abdel-Basset and Fedoroff, 1995). Although it is widely used in brain inflammatory studies, its action mechanism and signal transduction pathways are not fully elucidated. Several receptors for LPS were identified from a variety of studies. CD14, a GPIanchored glycoprotein expressed in monocytes/ macrophages, reacts with LPS (Wright et al., 1990). LPS forms a complex with LPS-binding protein (LBP) in serum (Wright et al., 1990). Apart from CD14, CD11C/CD18, a member of the leukocyte integrin family, also activates cells in response to LPS (Ingalls et al., 1998). Recently, toll-like receptor 4 (TIr4) was identified by positional cloning as the LPS signal transducer from the Lps locus, mutations of which abolish responses to LPS (Hoshino et al., 1999). A variety of intracellular signaling molecules, such as protein tyrosine kinases, mitogen-activated protein kinases, protein kinase $\mathrm{C}$, small $\mathrm{G}$ proteins, and ceramide-activated protein kinase are involved in LPS-mediated monocytes/ macrophage activation (Sweet and Hume, 1996). Through different signal transduction pathways, LPS activates transcription factors including NF-KB, NF-IL6, C/EBP and Fos/ Jun families, and induces iNOS, TNF- $\alpha, \mathrm{IL}-1 \beta$, IL-6, IL-12p40, TGF- $\beta$ and other cytokine genes (Sweet and Hume, 1996).

IFN- $\gamma$, released from activated Th1 and NK cells, activates macrophages/microglia to increase expression of MHC class I and class II. With LPS, it synergistically induces IL-12 production from microglia (Aloisi et al., 1997; Suzumura et al., 1998). IFN- $\gamma$-mediated activation involves the JAK-STAT pathway. Briefly, IFN- $\gamma$ stimulates the activation of receptor associated Jak1 and Jak2. This leads to the phosphorylation of a single receptor tyrosine residue, which is then recognized by the $\mathrm{SH} 2$ domain of Stat. It causes Stat phosphorylation followed by homodimerization, translocation into nucleus and induction of GAS (gamma-activation site) driven target genes (Schindler, 1999).

Chemokines are small proteins ( 8 to $10 \mathrm{kDa}$ ) that induce chemotaxis, tissue extravasation and functional modulation of a wide variety of leukocytes during inflammation (Taub, 1996). More than 40 distinct members are divided into 4 families typified by conservation of cysteine residues in the N-terminal sequence (Lusti-Narasimhan et al., 1996). Chemokines mediate their effects via $G$ protein-coupled receptors of the seven transmembrane domain (Horuk, 1994). A number of chemokines are expressed in the CNS. They are related to a number of diseases of the CNS including stroke, AIDS dementia, MS and AD (Mennicken et al., 1999). Fractalkine/neurotactin is a unique member of CX3C chemokine family which was discovered in 1997 (Bazan et al., 1997). In the CNS, several populations of neurons express fractalkine mRNA constitutively that is not affected by stimuli such as cytokines, LPS and toxic stimuli ( $A \beta$, glucose deprivation or glutamate) (Maciejewski-Lenoir et al., 1999). Membrane-bound fractalkine protein levels were decreased after excitotoxic glutamate stimuli (Chapman et al., 2000). Its receptor, CX3CR-1 is expressed at high levels in microglia (Nishiyori et al., 1998). Through its receptor, fractalkine induces intracellular $\mathrm{Ca}^{2+}$ mobilization, ERK activation and PI3-K-mediated PKB activation in microglia. It might be involved in regeneration of motor neurons after peripheral axotomy in facial motor neuron injury models (Harrison et al., 1998). Recent study demonstrated that CX3CR-1 deficiency dysregulates microglial responses, resulting in neurotoxicity (Cardona et al., 2006). Study showed that in the absence of CX3CR-1/fractalkine signaling, microglial responses to LPS and neurotoxic stimuli was altered. $C \times 3 \mathrm{cr}^{-/-}$mouse demonstrated more dopaminergic neuronal loss in MPTP-treated Parkinson's disease model and in a model of genetic motor neuron disease.

CD40 is a $45-50 \mathrm{kDa}$ transmembrane protein, which is a member of the TNFR superfamily (Vogel and Noelle, 1998). It has been shown that CD40 is constitutively expressed at low levels on microglia, and binding of microglial CD40 by CD40 ligand (CD40L) leads to marked TNF- $\alpha$ secretion, which is neurotoxic at such levels (Aloisi et al., 1999b; Tan et al., 1999a). Activation of ERK1/2 is involved in CD40-CD40L mediated microglial activation (Tan et al., 2000a). Interestingly, stimulation with $A \beta$ peptides and CD40L results in increased CD40 ex- 
pression on microglia followed by TNF- $\alpha$ secretion (Tan et al., 1999b). Recently, it has been demonstrated that CD45 suppresses CD40L-induced microglial activation via negative regulation of the Src/ERK1/2 cascade (Tan et al., 2000b).

Amyloid- $\beta$ peptide $(A \beta)$ is the principal component of the extracellular deposits in AD (Selkoe, 1989). $A \beta$ promotes neurite outgrowth, generates reactive oxygen intermediates, induces cytotoxic cellular oxidative stress, and microglial activation (Koo et al., 1993; Behl, 1997; Sasaki et al., 1997). Although the mechanism by which $A \beta$ peptides cause enhanced expression of proinflammatory cytokines from microglia, is not fully understood there is evidence that $A \beta$ may interact with cell-surface receptors, including receptors for advanced glycosylated endproducts (RAGE) and scavenger receptors (El Khoury et al., 1996; Yan et al., 1996). Additionally, calcium-, protein kinase $C$, and protein tyrosine kinase-dependent second messenger pathways have been postulated in $A \beta$ receptor-mediated signal transduction (Lorton, 1997; Combs et al., 1999). A $\beta$ peptide activates microglia through these signal transduction pathways to induce the secretion of neurotoxic substances including TNF- $\alpha$ and IL-1 $\beta$ (Mrak and Griffin, 2001; Smits et al., 2001). It may enhance neuroinflammation in $A D$ brain.

Gangliosides, sialic acid-containing glycosphingolipids, have also been reported as microglial activators (Pyo et al., 1999). Gangliosides exist in mammalian cell membranes and are particularly rich in the neuronal cell membrane. Gangliosides induce production of nitric oxide, TNF- $\alpha$ and cyclooxygenase-2 (COX-2) in microglia by activation of MAPKs (Pyo et al., 1999). Recent studies show that signals are released from neurons when they start to die. Upon potassium deprivation, cerebellar granule cells release signal molecules that can activate microglia (Tanaka et al., 1998). Supernatant from serum-deprived immortalized motor neurons can also activate microglia and induce release of NO that causes neuronal death (He and Strong, 2000). These signals from dying neurons may be potent candidates for microglial activation.

Thrombin-mediated microglial activation has been reported (Moller et al., 2000; Suo et al., 2002). Thrombin is generated from the precursor prothrombin that is endogenously expressed in human, mouse, and rat brain, including dopaminergic neurons in the SN (Dihanich et al., 1991; Soifer et al., 1994; Weinstein et al., 1995). Thrombin-induced microglial activation involves protease-activated receptor-1 (PAR-1) (Suo et al., 2002). Recent studies demonstrated that direct injection of thrombin into various brain parenchyma including hippocampus and substantia nigra results in induction of
iNOS, COX-2 and NADPH oxidase-mediated superoxide generation from microglial and subsequent neuronal degeneration (Choi et al., 2003; 2005).

We have recently identified matrix metalloproteinase-3 as a signaling molecule that is released from apoptotic cells and elicit microglial activation (Kim et al., 2005). This will be discussed in detail later.

\section{Roles of activated microglia in degenerative human brain disorders}

The most characteristic feature of microglia is their rapid activation in response to pathological change in the CNS. They respond not only to changes in the brain parenchymal integrity but also to very small alterations in their microenvironment, such as imbalances in ion homeostasis that precede pathological changes (Gehrmann et al., 1993). Although they have a critical role in host defense by removing invading microorganisms and neoplastic cells, or by secreting neurotrophic factors, microglia may aggravate the effects of inflammation and cause neuronal degeneration. Activated microglia at the site of inflammation change their morphology, express increased levels of MHC antigens and become phagocytic (Hayes et al., 1987; 1988). They release inflammatory cytokines that amplify the inflammatory response by activating and recruiting other cells to the brain lesion. In addition, microglia can release potent neurotoxins, such as TNF- $\alpha$ and others, which may cause neuronal damage. There are several neurodegenerative diseases in which microglial activation and microglial function may play a more significant role in mediating the diseases than in protecting neurons. Among them are HIV infection of the CNS, MS, AD and PD (McGeer et al., 1988; Raine, 1994; Dickson, 1997; Banati et al., 1998).

\section{HIV}

Approximately $20 \%$ of HIV-infected individuals develop a neurological syndrome consisting of motor dysfunction, cognitive deterioration and coma in later stages. The most characteristic feature of HIV-infected brain is that virus is concentrated in microglia and macrophages, with a very limited infection of astrocytes, endothelial cells, or neurons (Gabuzda et al., 1986; Wiley et al., 1986). Recent studies have suggested the model in which HIV entry into the CNS is mediated by circulating lymphocytes or monocytes, which in turn transmit virus to perivascular macrophages and microglia (Lane et al., 1996). The virus may replicate enough in infected microglia and macrophages to maintain a cycle of new infection. Infected microglia secrete several candidate neuro- 
toxins, such as viral proteins (gp120, tat and nef), cytokines, chemokines, arachidonic acid, and nitric oxide, to induce neuronal death or injury.

\section{MS}

Pathological studies on MS brain demonstrate the important role of macrophages and microglia in MS demyelination. Experimental allergic encephalomyelitis (EAE), a disease induced in rats or mice by immunization against components of myelin, has been widely used as an MS animal model. The earliest lesion in EAE is characterized by T-cell infiltration, which is eventually followed by recruitment of inflammatory cells, including activated macrophages and microglia. These cells secrete cytokines and other potent neurotoxins and result in neurological damage. Microglia may have a role in the induction of the initial inflammatory reaction by antigen presenting. T-cell recruitment by microglial antigen-presenting activity in turn enhances microglial activation and they aggravate the damage of oligodendrocytes, myelin and axon by releasing neurotoxins (Raine, 1994).

\section{AD}

$A D$ is a degenerative disorder characterized pathologically by $\beta$ amyloid-containing extracellular plaques and intraneuronal neurofibrillary tangles (NFTs) (Goedert et al., 1991). A large number of microglia form clusters around senile plaques. Initial detection of activated microglia in AD tissue used antibodies to the class II major MHC protein HLA-DR (McGeer et al., 1987). They also demonstrated that HLA-DR protein was more abundantly expressed on microglia that are closely associated with areas of degenerative lesion in tissue from AD patients. The finding of microglial clustering around senile plaques demonstrated that microglia are trying to phagocytose and remove toxic $A \beta$ plaques. However, microglia are known to produce many cytotoxic agents including proteolytic enzymes, cytokines, excitatory amino acids, quinolinic acid, complement proteins, reactive oxygen intermediates, and nitric oxide (Chao et al., 1992; Cassarino et al., 1997; McGuire et al., 2001; Liu et al., 2002). In addition, A $\beta$ can not only recruit and induce phagocytic activity of microglia, but also synthetic $A \beta$ also can induce the secretion of these cytotoxic agents (Meda et al., 1995; Sasaki et al., 1997). Therefore, it is conceivable that microglia, rather than being protective, may aggravate neurotoxicity in $A D$ brain.

\section{PD}

$\mathrm{PD}$ is a common neurodegenerative disorder cha- racterized by the degeneration of dopaminergic neurons in the substantia nigra pars compacta (SNpc) and the consequent loss of their projecting fibers in the striatum (Olanow and Tatton, 1999). The presence of oxidative stress and inflammatory activity is one of the significant pathological features of PD (Dexter et al., 1994; Hirsch et al., 1998). It has been shown that the levels of cytokines such as TNF- $\alpha$, IL- $1 \beta$ and IFN- $\gamma$ are elevated by 7 - to 15 -fold in the SN of PD patients (Mogi et al., 1994; Hirsch et al., 1998). Since microglia are a principal source of these cytokines, the data support microglial involvement in the pathogenesis of PD. Activated microgliamediated dopaminergic neuronal degeneration has been demonstrated in recent studies using animal models. Gao et al., (2002) showed that microglia play a pivotal role in rotenone-induced dopaminergic neuronal degeneration. Wu et al., (2002) demonstrated that the inhibition of microglial activation prevents dopaminergic neuronal loss in MPTP-treated mice. Microglial role in PD patogenesis will be discussed in depth (Figure 3).

\section{Pathological dynamics of activated microglia in pathogenesis of PD}

Activated microglia have been implicated in the pathogenesis and progress of PD. Characteristic pathological features of the PD brain are a selective and progressive loss of dopamine neurons of the substantia nigra (SN) and focal accumulation of activated microglia in the SN (McGeer et al., 1988; Forno, 1996; Banati et al., 1998; Knott et al., 2000; Mirza et al., 2000). Activation of microglia also has been identified in the $\mathrm{SN}$ and/or striatum of the parkinsonian animal models, such as 1-methyl-4phenyl-1,2,3,6-tetrahydropyridine (MPTP)-induced parkinsonian brain (O'Callaghan et al., 1990; Francis et al., 1995; Czlonkowska et al., 1996; Kohutnicka et al., 1998; Kurkowska-Jastrzebska et al., 1999) or medial forebrain bundle (MFB), which transmits axons from the nigral dopamine neurons to the striatum, axotomized rat brain (Brecknell et al., 1995; Revuelta et al., 1999; Sugama et al., 2003). Our recent study elucidated the neuropathological dynamics of activated microglia and their pathophysiological role during delayed neuronal loss in the SN (Cho et al., 2006). In this study, we examined immunophenotypic and morphological changes of activated microglia, as well as their temporal and spatial relationship with degenerating dopamine neurons after medial forebrain bundle (MFB) axotomy in the rat brain. Activated microglia appeared in the MFB and SN as early as 1-3 days post-lesion $(\mathrm{dpl})$, when there was no apparent SN dopamine 


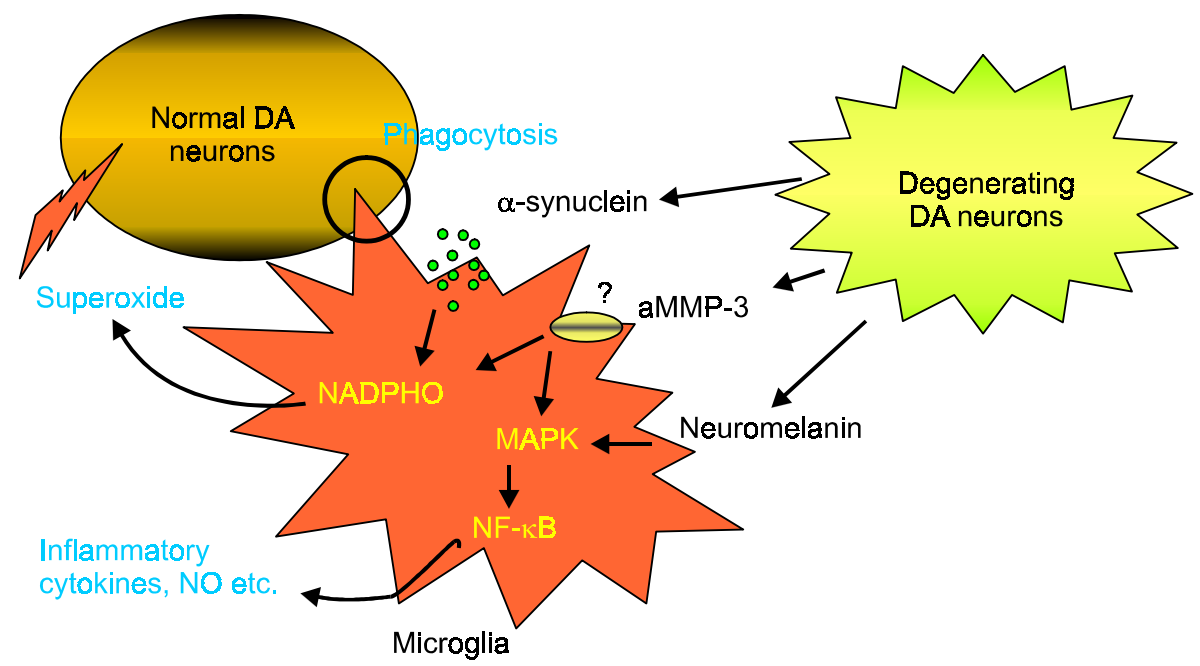

Figure 3. Microglia-mediated self-perpetuating dopamine (DA) neuronal degeneration model of PD. Various stimuli (either internal or external) initiating dopamine degeneration result in microglial activation through stimulatory signaling molecules such as aMMP-3 (active form of MMP-3), $\alpha$-synuclein and neuromelanin leakage. aMMP-3 induces NADPH oxidase (NADPHO)-derived superoxide release and NF-KB-mediated proinflammatory cytokine release through yet undefined pathway, probably protease-activity related receptor. Neuromelanin elicits microglial proinflammatory cytokine and NO release through NF-KB pathway. It has not been investigated yet whether it causes NADPHO-derived superoxide generation. $\alpha$-synuclein, especially aggregated form causes NADPHO-mediated superoxide release via phagocytosis-dependent pathway. Activated microglia cause dopamine neuronal degeneration either by superoxide, NO and other proinflammatory cytokines or by direct phagocytosis against normal neurons. This self-propelling degeneration cycles sustain chronic inflammatory condition and eventually induce progressive degeneration.

neuronal degeneration. Thereafter, a great number of activated microglia selectively adhered to degenerating axons, dendrites and dopamine neuronal somas of the SN. Thereafter, significant loss of these fibers and nigral dopamine neurons was observed. Although phenotypical activation of microglia was most pronounced between 14-28 dpl and gradually subsided, phagocytic microglia persisted until $70 \mathrm{dpl}$. All phagocytic microglia sticking to dopamine neurons showed activated but ramified form with enlarged somas and thickened processes. They were recruited to the SNc from cranial, dorsal and ventral aspects along various structures and finally stuck to dopamine neurons of the SNc. Characteristic rod-shaped microglia in the white matter were thought to migrate a long distance (Cho et al., 2006). Our results strongly suggests that neurons undergoing delayed neurodegeneration may be phagocytosed by numerous phagocytic, ramified microglia at various sites where specific surface signals are exposed or diffusible molecules are released. In addition, our earlier results (Sugama et al., 2003) showed that activated microglia were phargocytosing dopamine neuronal fibers at early stage of neuronal degeneration, suggesting that microglial phagocytosis of degenerating neurons is early occurring in neuronal degeneration, starting phagocytosis at the extending fibers, such as neurite extended to the $\mathrm{SN}$ reticulata. These results imply that degenerating neurons may release microgliaactivating signals much earlier stages of neuronal degeneration, and activated microglia start ingesting the nerve fibers piece-by-piece (Sugama et al., 2003). Our recent unpublished data (Cho et al., 2006) also showed that ramified microglia, probably after digestion of pieces of degenerating neurons, increased their sizes, which are nearly equivalent to the size of neuronal cell bodies (approximately 50 $\mu \mathrm{m})$, and apposed onto neighboring, bystander, nondegenerating neurons. The electron micrographic analysis of these microglia suggested that large, ramified microglia phagocytose bystander dopamine neurons, suggesting that activated microglial participation in the progressive degeneration of dopamine neurons (Cho et al., unpublished).

\section{Matrix metalloproteinase-3 (MMP-3)}

Although a number of studies have demonstrated microglial activation and its involvement in progressive neuronal degeneration upon dopamine neuronal damage, molecular mechanism underlying microglial 
activation and signals responsible for chronic microglial inflammatory response are still disputed. Our previous study identified matrix metalloproteinase-3 (MMP-3), a proteinase known to degrade extracellular matrix (ECM) component, as a candidate which intermediates neuronal apoptosis and microglial activation. In this study, we demonstrated that catalytically active from of MMP-3 (actMMP-3) is released from apoptotic PC12 cells grown in serumdeprived medium. actMMP-3 release occurred as early as $2 \mathrm{hr}$ after serum deprivation, even before cellular morphological change. actMMP-3 led to production of microglial inflammatory cytokines such as TNF- $\alpha$ through $E R K-N F_{\kappa} B$ signal transduction pathway, which in turn exacerbated neural cell degeneration (Kim et al., 2005). In our current work, MMP-3 expression and release were also shown in primary mesencephalic culture treated with 1-methyl4-phenylpyridinium (MPP+), a toxic metabolite of MPTP, a specific dopamine toxin. MPP+ treatment resulted in dopamine cell-specific expression of MMP-3 and dose dependent increase of actMMP-3 in culture medium. The released actMMP-3 as well as catalytically active recombinant MMP-3 (cMMP-3) led to microglial activation and superoxide generation in microglia and enhanced dopamine cell death. cMMP-3 caused dopamine cell death in mesencephalic neuron-glia mixed culture of wildtype mice but this was attenuated in the culture of NADPH oxidase (NADPHO) subunit null mice $\left(\right.$ gp $\left.91^{\text {phox-l- }}\right)$, suggesting that NADPHO mediated the cMMP-3-induced microglial production of superoxide and dopamine cell death (Kim et al., in press). This is critical finding to understand microgliosis in PD, as previous studies have identified that NADPHO-mediated microglial superoxide production is a mandatory microglial component to contribute MPP+ and MPTP induced dopamine toxicity both in vivo and in vitro (Wu et al., 2002; Gao et al., 2003). Furthermore, in the MPTP-injected animal model of PD, nigrostriatal dopamine neuronal degeneration, microglial activation and superoxide generation were largely attenuated in MMP-3-/- mice. Together, these data indicate that actMMP-3 released from stressed dopamine neurons is responsible for microglial activation and generation of NADPHO-derived superoxide, and eventually propagates nigrostriatal dopamine neuronal degeneration.

\section{$\alpha$-Synuclein}

Cytoplasmic accumulation of fibrillar $\alpha$-synuclein in Lewy bodies (Spillantini et al., 1997), the pathological hallmark of PD, may play a pivotal role in the onset and progression of Parkinson's as well as other neurodegenerative diseases. Although path- ophysiological role of this protein in the dopamine degeneration is still not clear, a wealth of evidence suggest that abnormal accumulation and aggregation of wild type or mutants (A53T, A30P and E46K) $\alpha$-synuclein may directly cause dopamine neuronal death. $\alpha$-synuclein is generally considered an intracellular protein, because of the lack of signal sequence and its abundant presence in the cytosol. However, recent studies proved that small portion of newly synthesized $\alpha$-synuclein is secreted from cells. Interestingly, the intravesicular $\alpha$-synuclein has increased aggregation tendency, secretion of both monomeric and aggregated $\alpha$-synuclein is elevated in response to proteasomal and mitochondrial dysfunction (Lee et al., 2005). Evidence of $\alpha$-synuclein release from cells is the presence of full length $\alpha$-synuclein in cerebrospinal fluid from Parkinson's disease and normal subjects (Borghi et al., 2000), and in human plasma (El-Agnaf et al., 2003). Several studies demonstrated that extracellular Lewy bodies and $\alpha$-synuclein-immunoreactive nigral aggregates are often surrounded by microglial or inflammatory mediator such as complements (McGeer et al., 1988; Yamada et al., 1992). Recent interesting study by Zhang et al. implies that microglia can enhance $\alpha$-synuclein-induced dopamine toxicity (2005). They also showed that $\alpha$-synuclein aggregates fail to induce dopamine neurotoxicity in microglial-depleted mesencephalic culture at low concentration. $\alpha$-synuclein aggregates induced intracellular ROS in microglia and superoxide release. Since cytochalasin $D$, an inhibitor of phagocytosis, inhibited $\alpha$-synuclein-mediated ROS generation in microglia, implying that phagocytosis is a critical component of the $\alpha$-synuclein aggregates-mediated microglial activation.

\section{Neuromelanin}

Neuromelanin is the dark insoluble macromolecule that confers the black (substantia nigra) or grey (locus coeruleus) color to monoaminergic basal ganglia. Neuromelanin accumulates in normal healthy human SN with age. Normally, neuromelanin is considered to play a protective role intracellularly by binding toxic metabolite produced in $\mathrm{SN}$ cells such as dopamine and metals (D'Amato et al., 1986; Lindquist et al., 1988; Zecca et al., 1994) and serve as an antioxidant (Fornstedt et al., 1989; Wilczok et al., 1999). However, it has been also suggested that neuromelanin can be potentially toxic to dopamine neurons, as excess neuromelanin directly inhibits proteasomal function (Shamoto-Nagai et al., 2004; Shamoto-Nagai et al., 2006). Several studies showed that neuromelanin also exists outside dopamine neurons. Extraneuronal melanin was found in pa- 
tients suffering from juvenile (Ishikawa and Takahashi, 1998), idiopathic, and MPTP-induced parkinsonism (Langston et al., 1999). In an autopsy study of a patient with MPTP-induced parkinsonism, extraneuronal melanin was found in close vicinity to activated microglial cells even 12 years after exposure to the neurotoxin. This suggests that neuromelanin interacts with microglia. By adding neuromelanin extracted from PD brain to microglia culture, Wilm et al. showed that neuromelanin has chemotactic effects, and induces microglial proinflammatory cytokines such as TNF- $\alpha$, IL- 6 and NO through p38 MAPK-NFKB signal transduction pathways. Those molecules have been implicated as factors involved in PD pathogenesis (Wilms et al., 2003).

Molecules such as MMP-3, $\alpha$-synuclein and neuromelanin that can be released from damaged dopamine neurons might form self-perpetuating vicious cycles of neuronal degeneration by augmenting microglial activation and eventually lead to chronic inflammation.

\section{Conclusion}

Activation of microglia is implicated in the pathogenesis of various neurodegenerative diseases which are characterized by long-term progressive nature of degeneration. A number of stimuli might trigger neuronal death under various circumstances and microglia might be activated either by various signals released from dying neurons or by direct contact to damaged neurons. By releasing toxic molecules including superoxide, or by actively phagocytosing by-stander neighboring cells, activated microglia may form vicious self-perpetuating neuronal degeneration cycle. Thus, intervention of microglial activation process will become a promising therapeutic target for the treatment of a number of neurodegenerative conditions (Figure 3).

\section{Acknowledgement}

We thank Drs. BP Cho and OY Hwang for insightful discussion and suggestion. The authors are grateful to Drs. SY Kim and DH Choi for critical reading of the manuscript.

\section{References}

abd-el-Basset E, Fedoroff S. Effect of bacterial wall lipopolysaccharide (LPS) on morphology, motility, and cytoskeletal organization of microglia in cultures. J Neurosci Res 1995; 41:222-37

Akassoglou K, Bauer J, Kassiotis G, Pasparakis M, Lassmann H, Kollias G, Probert L. Oligodendrocyte apoptosis and pri- mary demyelination induced by local TNF/p55TNF receptor signaling in the central nervous system of transgenic mice: models for multiple sclerosis with primary oligodendrogliopathy. Am J Pathol 1998;153:801-13

Alliot F, Godin I, Pessac B. Microglia derive from progenitors, originating from the yolk sac, and which proliferate in the brain. Brain Res Dev Brain Res 1999;117:145-52

Aloisi F, De Simone R, Columba-Cabezas S, Levi G. Opposite effects of interferon-gamma and prostaglandin E2 on tumor necrosis factor and interleukin-10 production in microglia: a regulatory loop controlling microglia pro- and anti-inflammatory activities. J Neurosci Res 1999a;56:571-80

Aloisi F. Immune function of microglia. Glia 2001;36:165-79

Aloisi F, Penna G, Cerase J, Menendez Iglesias B, Adorini L. IL-12 production by central nervous system microglia is inhibited by astrocytes. J Immunol 1997;159:1604-12

Aloisi F, Penna G, Polazzi E, Minghetti L, Adorini L. CD40-CD154 interaction and IFN-gamma are required for IL-12 but not prostaglandin E2 secretion by microglia during antigen presentation to Th1 cells. J Immunol 1999b;162: 1384-91

Aloisi F, Ria F, Penna G, Adorini L. Microglia are more efficient than astrocytes in antigen processing and in Th1 but not Th2 cell activation. J Immunol 1998;160:4671-80

An SF, Ciardi A, Giometto B, Scaravilli T, Gray F, Scaravilli F. Investigation on the expression of major histocompatibility complex class II and cytokines and detection of HIV-1 DNA within brains of asymptomatic and symptomatic HIV-1-positive patients. Acta Neuropathol (Berl) 1996;91:494-503

Andersson PB, Perry VH, Gordon S. The acute inflammatory response to lipopolysaccharide in CNS parenchyma differs from that in other body tissues. Neuroscience 1992;48:169-86

Appel K, Honegger P, Gebicke-Haerter PJ. Expression of interleukin-3 and tumor necrosis factor-beta mRNAs in cultured microglia. J Neuroimmunol 1995;60:83-91

Banati RB, Daniel SE, Blunt SB. Glial pathology but absence of apoptotic nigral neurons in long-standing Parkinson's disease. Mov Disord 1998;13:221-7

Barker CF, Billingham RE. Immunologically privileged sites. Adv Immunol 1977;25:1-54

Bazan JF, Bacon KB, Hardiman G, Wang W, Soo K, Rossi D, Greaves DR, Zlotnik A, Schall TJ. A new class of membrane-bound chemokine with a CX3C motif. Nature 1997; 385:640-4

Becher B, Barker PA, Owens T, Antel JP. CD95-CD95L: can the brain learn from the immune system? Trends Neurosci 1998;21:114-7

Becher B, Durell BG, Noelle RJ. IL-23 produced by CNS-resident cells controls $T$ cell encephalitogenicity during the effector phase of experimental autoimmune encephalomyelitis. J Clin Invest 2003;112:1186-91

Bechmann I, Kwidzinski E, Kovac AD, Simburger E, Horvath T, Gimsa U, Dirnagl U, Priller J, Nitsch R. Turnover of rat brain perivascular cells. Exp Neurol 2001;168:242-9 
Bechmann I, Mor G, Nilsen J, Eliza M, Nitsch R, Naftolin F. FasL (CD95L, Apo1L) is expressed in the normal rat and human brain: evidence for the existence of an immunological brain barrier. Glia 1999;27:62-74

Behl C. Amyloid beta-protein toxicity and oxidative stress in Alzheimer's disease. Cell Tissue Res 1997;290:471-80

Benveniste EN. Cytokine actions in the central nervous system. Cytokine Growth Factor Rev 1998;9:259-75

Borghi R, Marchese R, Negro A, Marinelli L, Forloni G, Zaccheo D, Abbruzzese G, Tabaton M. Full length alpha-synuclein is present in cerebrospinal fluid from Parkinson's disease and normal subjects. Neurosci Lett 2000;287:65-7

Brecknell JE, Dunnett SB, Fawcett JW. A quantitative study of cell death in the substantia nigra following a mechanical lesion of the medial forebrain bundle. Neuroscience 1995;64:219-27

Broderick C, Duncan L, Taylor N, Dick AD. IFN-gamma and LPS-mediated IL-10-dependent suppression of retinal microglial activation. Invest Ophthalmol Vis Sci 2000;41:2613-22

Buttini M, Boddeke H. Peripheral lipopolysaccharide stimulation induces interleukin-1 beta messenger RNA in rat brain microglial cells. Neuroscience 1995;65:523-30

Cardona AE, Pioro EP, Sasse ME, Kostenko V, Cardona SM, Dijkstra IM, Huang D, Kidd G, Dombrowski S, Dutta R, Lee JC, Cook DN, Jung S, Lira SA, Littman DR, Ransohoff RM. Control of microglial neurotoxicity by the fractalkine receptor. Nat Neurosci 2006;9:917-24

Carson MJ, Reilly CR, Sutcliffe JG, Lo D. Mature microglia resemble immature antigen-presenting cells. Glia 1998;22: 72-85

Carson MJ, Sutcliffe JG, Campbell IL. Microglia stimulate naive T-cell differentiation without stimulating T-cell proliferation. J Neurosci Res 1999;55:127-34

Cassarino DS, Fall CP, Swerdlow RH, Smith TS, Halvorsen EM, Miller SW, Parks JP, Parker WD Jr, Bennett JP Jr. Elevated reactive oxygen species and antioxidant enzyme activities in animal and cellular models of Parkinson's disease. Biochim Biophys Acta 1997;1362:77-86

Chao CC, Hu S, Molitor TW, Shaskan EG, Peterson PK. Activated microglia mediate neuronal cell injury via a nitric oxide mechanism. J Immunol 1992;149:2736-41

Chapman GA, Moores K, Harrison D, Campbell CA, Stewart $B R$, Strijbos PJ. Fractalkine cleavage from neuronal membranes represents an acute event in the inflammatory response to excitotoxic brain damage. J Neurosci 2000;20: $\mathrm{RC} 87$

Cho BP, Song DY, Sugama S, Shin DH, Shimizu Y, Kim SS, Kim YS, Joh TH. Pathological dynamics of activated microglia following medial forebrain bundle transection. Glia 2006;53: 92-102

Choi SH, Joe EH, Kim SU, Jin BK. Thrombin-induced microglial activation produces degeneration of nigral dopaminergic neurons in vivo. J Neurosci 2003;23:5877-86

Choi SH, Lee da Y, Kim SU, Jin BK. Thrombin-induced oxidative stress contributes to the death of hippocampal neurons in vivo: role of microglial NADPH oxidase. J Neurosci 2005;25:
4082-90

Combs CK, Johnson DE, Cannady SB, Lehman TM, Landreth $\mathrm{GE}$. Identification of microglial signal transduction pathways mediating a neurotoxic response to amyloidogenic fragments of beta-amyloid and prion proteins. J Neurosci 1999;19: 928-39

Cserr HF, Knopf PM. Cervical lymphatics, the blood-brain barrier and the immunoreactivity of the brain: a new view. Immunol Today 1992;13:507-12

Czlonkowska A, Kohutnicka M, Kurkowska-Jastrzebska I, Czlonkowski A. Microglial reaction in MPTP (1-methyl-4-phenyl-1,2,3,6-tetrahydropyridine) induced Parkinson's disease mice model. Neurodegeneration 1996;5:137-43

D'Amato RJ, Lipman ZP, Snyder SH. Selectivity of the parkinsonian neurotoxin MPTP: toxic metabolite MPP+ binds to neuromelanin. Science 1986;231:987-9

Davalos D, Grutzendler J, Yang G, Kim JV, Zuo Y, Jung S, Littman DR, Dustin ML, Gan WB. ATP mediates rapid microglial response to local brain injury in vivo. Nat Neurosci 2005; 8:752-8

Dexter DT, Holley AE, Flitter WD, Slater TF, Wells FR, Daniel SE, Lees AJ, Jenner P, Marsden CD. Increased levels of lipid hydroperoxides in the parkinsonian substantia nigra: an HPLC and ESR study. Mov Disord 1994;9:92-7

Dickson, DW. The pathogenesis of senile plaques. J Neuropathol Exp Neurol 1997;56:321-39

Dihanich M, Kaser M, Reinhard E, Cunningham D, Monard D. Prothrombin mRNA is expressed by cells of the nervous system. Neuron 1991;6:575-81

Dorries R. The role of T-cell-mediated mechanisms in virus infections of the nervous system. Curr Top Microbiol Immunol 2001;253:219-45

El Khoury J, Hickman SE, Thomas CA, Cao L, Silverstein SC, Loike JD. Scavenger receptor-mediated adhesion of microglia to beta-amyloid fibrils. Nature 1996;382:716-9

El-Agnaf OM, Salem SA, Paleologou KE, Cooper LJ, Fullwood NJ, Gibson MJ, Curran MD, Court JA, Mann DM, Ikeda S, Cookson MR, Hardy J, Allsop D. Alpha-synuclein implicated in Parkinson's disease is present in extracellular biological fluids, including human plasma. Faseb J 2003;17:1945-7

Fischer HG, Reichmann G. Brain dendritic cells and macrophages/microglia in central nervous system inflammation. J Immunol 2001;166:2717-26

Flugel A, Schwaiger FW, Neumann H, Medana I, Willem M, Wekerle H, Kreutzberg GW, Graeber MB. Neuronal FasL induces cell death of encephalitogenic T lymphocytes. Brain Pathol 2000;10:353-64

Ford AL, Foulcher E, Lemckert FA, Sedgwick JD. Microglia induce CD4 T lymphocyte final effector function and death. J Exp Med 1996;184:1737-45

Forno LS. Neuropathology of Parkinson's disease. J Neuropathol Exp Neurol 1996;55:259-72

Fornstedt B, Brun A, Rosengren E, Carlsson A. The apparent autoxidation rate of catechols in dopamine-rich regions of hu- 
man brains increases with the degree of depigmentation of substantia nigra. J Neural Transm Park Dis Dement Sect 1989; 1:279-95

Francis JW, Von Visger J, Markelonis GJ, Oh TH. Neuroglial responses to the dopaminergic neurotoxicant 1-methyl-4-phenyl-1,2,3,6-tetrahydropyridine in mouse striatum. Neurotoxicol Teratol 1995;17:7-12

Frei K, Lins H, Schwerdel C, Fontana A. Antigen presentation in the central nervous system. The inhibitory effect of IL-10 on $\mathrm{MHC}$ class II expression and production of cytokines depends on the inducing signals and the type of cell analyzed. $\mathrm{J}$ Immunol 1994; 152:2720-8

Gabuzda DH, Ho DD, de la Monte SM, Hirsch MS, Rota TR, Sobel RA. Immunohistochemical identification of HTLV-III antigen in brains of patients with AIDS. Ann Neurol 1986;20: 289-95

Gao HM, Liu B, Zhang W, Hong JS. Critical role of microglial NADPH oxidase-derived free radicals in the in vitro MPTP model of Parkinson's disease. Faseb J 2003;17:1954-6

Gehrmann J, Banati RB, Kreutzberg GW. Microglia in the immune surveillance of the brain: human microglia constitutively express HLA-DR molecules. J Neuroimmunol 1993;48:18998

Goedert M, Sisodia SS, Price DL. Neurofibrillary tangles and beta-amyloid deposits in Alzheimer's disease. Curr Opin Neurobiol 1991;1:441-7

Gozes I, Bassan M, Zamostiano R, Pinhasov A, Davidson A, Giladi E, Perl O, Glazner GW, Brenneman DE. A novel signaling molecule for neuropeptide action: activity-dependent neuroprotective protein. Ann N Y Acad Sci 1999;897:125-35

Graeber MB, Grasbon-Frodl E, Eitzen UV, Kosel S. Neurodegeneration and aging: role of the second genome. $J$ Neurosci Res 1998;52:1-6

Harrison JK, Jiang Y, Chen S, Xia Y, Maciejewski D, McNamara RK, Streit WJ, Salafranca MN, Adhikari S, Thompson DA, Botti P, Bacon KB, Feng L. Role for neuronally derived fractalkine in mediating interactions between neurons and CX3CR1-expressing microglia. Proc Natl Acad Sci USA 1998; 95:10896-901

Hayes GM, Woodroofe MN, Cuzner ML. Microglia are the major cell type expressing MHC class II in human white matter. J Neurol Sci 1987;80:25-37

Hayes GM, Woodroofe MN, Cuzner ML. Characterisation of microglia isolated from adult human and rat brain. J Neuroimmunol 1988;19:177-89

He BP, Strong MJ. A morphological analysis of the motor neuron degeneration and microglial reaction in acute and chronic in vivo aluminum chloride neurotoxicity. J Chem Neuroanat 2000;17:207-15

Hickey WF, Vass K, Lassmann H. Bone marrow-derived elements in the central nervous system: an immunohistochemical and ultrastructural survey of rat chimeras. J Neuropathol Exp Neurol 1992; 51:246-56

Hirsch EC, Hunot S, Damier P, Faucheux B. Glial cells and inflammation in Parkinson's disease: a role in neurodege- neration? Ann Neurol 1998;44:S115-20

Hoek RM, Ruuls SR, Murphy CA, Wright GJ, Goddard R, Zurawski SM, Blom B, Homola ME, Streit WJ, Brown MH, Barclay AN, Sedgwick JD. Down-regulation of the macrophage lineage through interaction with OX2 (CD200). Science 2000; 290:1768-71

Horuk R. Molecular properties of the chemokine receptor family. Trends Pharmacol Sci 1994;15:159-65

Hoshino K, Takeuchi O, Kawai T, Sanjo H, Ogawa T, Takeda Y, Takeda K, Akira S. Cutting edge: Toll-like receptor 4 (TLR4)-deficient mice are hyporesponsive to lipopolysaccharide: evidence for TLR4 as the Lps gene product. J Immunol 1999;162:3749-52

Ingalls RR, Arnaout MA, Delude RL, Flaherty S, Savedra R Jr, Golenbock DT. The CD11/CD18 integrins: characterization of three novel LPS signaling receptors. Prog Clin Biol Res 1998; 397:107-17

Irani DN. Brain-derived gangliosides induce cell cycle arrest in a murine T cell line. J Neuroimmunol 1998;87:11-6

Ishikawa A, Takahashi H. Clinical and neuropathological aspects of autosomal recessive juvenile parkinsonism. J Neurol 1998;245:P4-9

Kim YS, Choi DH, Block ML, Lorenzl S, Yang L, Kim YJ, Sugama S, Cho BP, Hwang O, Browne SE, Kim SY, Hong J-S, Beal MF, Joh TH. A pivotal role of matrix metalloproteinase-3 activity in dopaminergic neuronal degeneration via microglial activation. FASEB Journal (in press)

Kim YS, Kim SS, Cho JJ, Choi DH, Hwang O, Shin DH, Chun HS, Beal MF, Joh TH. Matrix metalloproteinase-3: a novel signaling proteinase from apoptotic neuronal cells that activates microglia. J Neurosci 2005;25:3701-11

Knott C, Stern G, Wilkin GP. Inflammatory regulators in Parkinson's disease: iNOS, lipocortin-1, and cyclooxygenases-1 and -2. Mol Cell Neurosci 2000;16:724-39

Kohutnicka M, Lewandowska E, Kurkowska-Jastrzebska I, Czlonkowski A, Czlonkowska A. Microglial and astrocytic involvement in a murine model of Parkinson's disease induced by 1-methyl-4-phenyl-1,2,3,6-tetrahydropyridine (MPTP). Immunopharmacology 1998;39:167-80

Koo EH, Park L, Selkoe DJ. Amyloid beta-protein as a substrate interacts with extracellular matrix to promote neurite outgrowth. Proc Natl Acad Sci USA 1993;90:4748-52

Krogsgaard M, Wucherpfennig KW, Canella B, Hansen BE, Svejgaard A, Pyrdol J, Ditzel H, Raine C, Engberg J, Fugger $L$. Visualization of myelin basic protein (MBP) $T$ cell epitopes in multiple sclerosis lesions using a monoclonal antibody specific for the human histocompatibility leukocyte antigen (HLA)-DR2-MBP 85-99 complex. J Exp Med 2000;191:1395412

Kurkowska-Jastrzebska I, Wronska A, Kohutnicka M, Czlonkowski A, Czlonkowska $A$. The inflammatory reaction following 1-methyl-4-phenyl-1,2,3, 6-tetrahydropyridine intoxication in mouse. Exp Neurol 1999;156:50-61

Lane JH, Sasseville VG, Smith MO, Vogel P, Pauley DR, Heyes MP, Lackner AA. Neuroinvasion by simian immuno- 
deficiency virus coincides with increased numbers of perivascular macrophages/microglia and intrathecal immune activation. J Neurovirol 1996;2:423-32

Langston JW, Forno LS, Tetrud J, Reeves AG, Kaplan JA, Karluk $D$. Evidence of active nerve cell degeneration in the substantia nigra of humans years after 1-methyl-4-phenyl-1,2,3,6tetrahydropyridine exposure. Ann Neurol 1999;46:598-605

Lee HJ, Patel S, Lee SJ. Intravesicular localization and exocytosis of alpha-synuclein and its aggregates. J Neurosci 2005; 25:6016-24

Levi G, Minghetti L, Aloisi F. Regulation of prostanoid synthesis in microglial cells and effects of prostaglandin E2 on microglial functions. Biochimie 1998;80:899-904

Lindquist NG, Larsson BS, Lyden-Sokolowski A. Autoradiography of [14C]paraquat or [14C]diquat in frogs and mice: accumulation in neuromelanin. Neurosci Lett 1988;93:1-6

Liu B, Gao HM, Wang JY, Jeohn GH, Cooper CL, Hong JS. Role of nitric oxide in inflammation-mediated neurodegeneration. Ann N Y Acad Sci 2002;962:318-31

Lorton D. Beta-amyloid-induced IL-1 beta release from an activated human monocyte cell line is calcium- and G-proteindependent. Mech Ageing Dev 1997;94:199-211

Lusti-Narasimhan M, Chollet A, Power CA, Allet B, Proudfoot AE, Wells TN. A molecular switch of chemokine receptor selectivity. Chemical modification of the interleukin-8 Leu25 $\rightarrow$ Cys mutant. J Biol Chem 1996;271:3148-53

Maciejewski-Lenoir D, Chen S, Feng L, Maki R, Bacon KB. Characterization of fractalkine in rat brain cells: migratory and activation signals for CX3CR-1-expressing microglia. J Immunol 1999;163:1628-35

Maehlen J, Olsson T, Zachau A, Klareskog L, Kristensson K. Local enhancement of major histocompatibility complex (MHC) class I and II expression and cell infiltration in experimental allergic encephalomyelitis around axotomized motor neurons. J Neuroimmunol 1989;23:125-32

McGeer PL, Itagaki S, Boyes BE, McGeer EG. Reactive microglia are positive for HLA-DR in the substantia nigra of Parkinson's and Alzheimer's disease brains. Neurology 1988; 38:1285-91

McGeer PL, Itagaki S, Tago H, McGeer EG. Reactive microglia in patients with senile dementia of the Alzheimer type are positive for the histocompatibility glycoprotein HLA-DR. Neurosci Lett 1987;79:195-200

McGeer PL, Kawamata T, Walker DG, Akiyama H, Tooyama I, McGeer EG. Microglia in degenerative neurological disease. Glia 1993;7:84-92

McGuire SO, Ling ZD, Lipton JW, Sortwell CE, Collier TJ, Carvey PM. Tumor necrosis factor alpha is toxic to embryonic mesencephalic dopamine neurons. Exp Neurol 2001;169: 219-30

McMenamin PG. Distribution and phenotype of dendritic cells and resident tissue macrophages in the dura mater, leptomeninges, and choroid plexus of the rat brain as demonstrated in wholemount preparations. J Comp Neurol 1999; 405:553-62
Meda L, Cassatella MA, Szendrei GI, Otvos L Jr, Baron P, Villalba M, Ferrari D, Rossi F. Activation of microglial cells by beta-amyloid protein and interferon-gamma. Nature 1995; 374:647-50

Mellman I, Steinman RM. Dendritic cells: specialized and regulated antigen processing machines. Cell 2001;106:255-8

Mennicken F, Maki R, de Souza EB, Quirion R. Chemokines and chemokine receptors in the CNS: a possible role in neuroinflammation and patterning. Trends Pharmacol Sci 1999;20: 73-8

Mirza B, Hadberg H, Thomsen P, Moos T. The absence of reactive astrocytosis is indicative of a unique inflammatory process in Parkinson's disease. Neuroscience 2000;95:425-32

Mogi M, Harada M, Riederer P, Narabayashi H, Fujita K, Nagatsu T. Tumor necrosis factor-alpha (TNF-alpha) increases both in the brain and in the cerebrospinal fluid from parkinsonian patients. Neurosci Lett 1994;165:208-10

Moller T, Hanisch UK, Ransom BR. Thrombin-induced activation of cultured rodent microglia. J Neurochem 2000;75: 1539-47

Neumann $\mathrm{H}$. Control of glial immune function by neurons. Glia 2001;36:191-9

Neumann H, Misgeld T, Matsumuro K, Wekerle H. Neurotrophins inhibit major histocompatibility class II inducibility of microglia: involvement of the p75 neurotrophin receptor. Proc Natl Acad Sci USA 1998;95:5779-84

Nimmerjahn A, Kirchhoff F, Helmchen F. Resting microglial cells are highly dynamic surveillants of brain parenchyma in vivo. Science 2005;308:1314-8

Nishiyori A, Minami M, Ohtani Y, Takami S, Yamamoto J, Kawaguchi N, Kume T, Akaike A, Satoh M. Localization of fractalkine and CX3CR1 mRNAs in rat brain: does fractalkine play a role in signaling from neuron to microglia? FEBS Lett 1998; 429:167-72

O'Callaghan JP, Miller DB, Reinhard JF Jr. Characterization of the origins of astrocyte response to injury using the dopaminergic neurotoxicant, 1-methyl-4-phenyl-1,2,3,6-tetrahydropyridine. Brain Res 1990;521:73-80

Oh JW, Schwiebert LM, Benveniste EN. Cytokine regulation of $\mathrm{CC}$ and $\mathrm{CXC}$ chemokine expression by human astrocytes. J Neurovirol 1999;5:82-94

O'Keefe GM, Nguyen VT, Benveniste EN. Class II transactivator and class II MHC gene expression in microglia: modulation by the cytokines TGF-beta, IL-4, IL-13 and IL-10. Eur J Immunol 1999;29:1275-85

O'Keefe GM, Nguyen VT, Benveniste EN. Regulation and function of class II major histocompatibility complex, CD40, and B7 expression in macrophages and microglia: Implications in neurological diseases. J Neurovirol 2002;8:496-512

Olanow CW, Tatton WG. Etiology and pathogenesis of Parkinson's disease. Annu Rev Neurosci 1999;22:123-44

Owens T. Identification of new therapeutic targets for prevention of CNS inflammation. Expert Opin Ther Targets 2002; 6:203-15 
Pazmany T, Kosa JP, Tomasi TB, Mechtler L, Turoczi A, Lehotzky A. Effect of transforming growth factor-beta1 on microglial MHC-class II expression. J Neuroimmunol 2000;103: $122-30$

Pender MP, Rist MJ. Apoptosis of inflammatory cells in immune control of the nervous system: role of glia. Glia 2001;36: $137-44$

Perry VH. A revised view of the central nervous system microenvironment and major histocompatibility complex class II antigen presentation. J Neuroimmunol 1998;90:113-21

Piehl F, Lidman O. Neuroinflammation in the rat--CNS cells and their role in the regulation of immune reactions. Immunol Rev 2001;184:212-25

Pyo H, Joe E, Jung S, Lee SH, Jou I. Gangliosides activate cultured rat brain microglia. J Biol Chem 1999;274:34584-9

Raine CS. Multiple sclerosis: immune system molecule expression in the central nervous system. J Neuropathol Exp Neurol 1994;53:328-37

Revuelta M, Venero JL, Machado A, Cano J. Serotonin hyperinnervation in the adult rat ventral mesencephalon following unilateral transection of the medial forebrain bundle. Correlation with reactive microglial and astroglial populations. Neuroscience 1999;91:567-77

Sasaki A, Yamaguchi H, Ogawa A, Sugihara S, Nakazato Y. Microglial activation in early stages of amyloid beta protein deposition. Acta Neuropathol (Berl) 1997;94:316-22

Schindler C. Cytokines and JAK-STAT signaling. Exp Cell Res 1999;253:7-14

Sedgwick JD, Riminton DS, Cyster JG, Korner H. Tumor necrosis factor: a master-regulator of leukocyte movement. Immunol Today 2000;21:110-3

Selkoe DJ. Amyloid beta protein precursor and the pathogenesis of Alzheimer's disease. Cell 1989;58:611-2

Serafini B, Columba-Cabezas S, Di Rosa F, Aloisi F. Intracerebral recruitment and maturation of dendritic cells in the onset and progression of experimental autoimmune encephalomyelitis. Am J Pathol 2000;157:1991-2002

Shamoto-Nagai M, Maruyama W, Akao Y, Osawa T, Tribl F, Gerlach M, Zucca FA, Zecca L, Riederer P, Naoi M. Neuromelanin inhibits enzymatic activity of $26 \mathrm{~S}$ proteasome in human dopaminergic SH-SY5Y cells. J Neural Transm 2004;111:1253-65

Shamoto-Nagai M, Maruyama W, Yi H, Akao Y, Tribl F, Gerlach M, Osawa T, Riederer P, Naoi M. Neuromelanin induces oxidative stress in mitochondria through release of iron: mechanism behind the inhibition of $26 \mathrm{~S}$ proteasome. J Neural Transm 2006;113:633-44

Shrikant $P$, Benveniste EN. The central nervous system as an immunocompetent organ: role of glial cells in antigen presentation. J Immunol 1996;157:1819-22

Soifer SJ, Peters KG, O'Keefe J, Coughlin SR. Disparate temporal expression of the prothrombin and thrombin receptor genes during mouse development. Am J Pathol 1994;144: $60-9$
Spillantini MG, Schmidt ML, Lee VM, Trojanowski JQ, Jakes R, Goedert M. Alpha-synuclein in Lewy bodies. Nature 1997; 388:839-40

Streit WJ, Kincaid-Colton CA. The brain's immune system. Sci Am 1995; 273:54-5,58-61

Sugama S, Cho BP, Degiorgio LA, Shimizu Y, Kim SS, Kim YS, Shin DH, Volpe BT, Reis DJ, Cho S, Joh TH. Temporal and sequential analysis of microglia in the substantia nigra following medial forebrain bundle axotomy in rat. Neuroscience 2003; 116:925-33

Suo Z, Wu M, Ameenuddin S, Anderson HE, Zoloty JE, Citron BA, Andrade-Gordon P, Festoff BW. Participation of protease-activated receptor-1 in thrombin-induced microglial activation. J Neurochem 2002;80:655-66

Suzumura A, Sawada M, Takayanagi T. Production of interleukin-12 and expression of its receptors by murine microglia. Brain Res 1998;787:139-42

Suzumura A, Sawada M, Yamamoto $H$, Marunouchi T. Transforming growth factor-beta suppresses activation and proliferation of microglia in vitro. J Immunol 1993;151:2150-8

Sweet MJ, Hume DA. Endotoxin signal transduction in macrophages. J Leukoc Biol 1996;60:8-26

Tan J, Town T, Mori T, Wu Y, Saxe M, Crawford F, Mullan M. CD45 opposes beta-amyloid peptide-induced microglial activation via inhibition of $\mathrm{p} 44 / 42$ mitogen-activated protein kinase. J Neurosci 2000a;20:7587-94

Tan J, Town T, Mullan M. CD45 inhibits CD40L-induced microglial activation via negative regulation of the Src/p44/42 MAPK pathway. J Biol Chem 2000b;275:37224-31

Tan J, Town T, Paris D, Mori T, Suo Z, Crawford F, Mattson MP, Flavell RA, Mullan M. Microglial activation resulting from CD40-CD40L interaction after beta-amyloid stimulation. Science 1999a;286:2352-5

Tan J, Town T, Saxe M, Paris D, Wu Y, Mullan M. Ligation of microglial CD40 results in p44/42 mitogen-activated protein kinase-dependent TNF-alpha production that is opposed by TGF-beta 1 and IL-10. J Immunol 1999b;163:6614-21

Tanaka S, Suzuki K, Watanabe M, Matsuda A, Tone S, Koike $T$. Upregulation of a new microglial gene, mrf- 1 , in response to programmed neuronal cell death and degeneration. J Neurosci 1998;18:6358-69

Taub DD. Chemokine-leukocyte interactions. The voodoo that they do so well. Cytokine Growth Factor Rev 1996;7:355-76

Taupin V, Renno T, Bourbonniere L, Peterson AC, Rodriguez $M$, Owens T. Increased severity of experimental autoimmune encephalomyelitis, chronic macrophage/microglial reactivity, and demyelination in transgenic mice producing tumor necrosis factor-alpha in the central nervous system. Eur $\mathrm{J}$ Immunol 1997;27:905-13

Tsirka SE. Clinical implications of the involvement of tPA in neuronal cell death. J Mol Med 1997;75:341-7

Vincent VA, Tilders FJ, Van Dam AM. Inhibition of endotoxin-induced nitric oxide synthase production in microglial cells by the presence of astroglial cells: a role for transforming growth factor beta. Glia 1997;19:190-8 
Vitkovic L, Maeda S, Sternberg E. Anti-inflammatory cytokines: expression and action in the brain. Neuroimmunomodulation 2001;9:295-312

Vogel LA, Noelle RJ. CD40 and its crucial role as a member of the TNFR family. Semin Immunol 1998;10:435-42

Wei R, Jonakait GM. Neurotrophins and the anti-inflammatory agents interleukin-4 (IL-4), IL-10, IL-11 and transforming growth factor-beta1 (TGF-beta1) down-regulate T cell costimulatory molecules B7 and CD40 on cultured rat microglia. J Neuroimmunol 1999;95:8-18

Weinstein JR, Gold SJ, Cunningham DD, Gall CM. Cellular localization of thrombin receptor mRNA in rat brain: expression by mesencephalic dopaminergic neurons and codistribution with prothrombin mRNA. J Neurosci 1995;15:2906-19

Wilczok T, Stepien K, Dzierzega-Lecznar A, Zajdel A, Wilczok A. Model neuromelanins as antioxidative agents during lipid peroxidation. Neurotox Res 1999; 1:141-7

Wiley CA, Schrier RD, Nelson JA, Lampert PW, Oldstone MB. Cellular localization of human immunodeficiency virus infection within the brains of acquired immune deficiency syndrome patients. Proc Natl Acad Sci USA 1986;83:7089-93

Williams K, Alvarez X, Lackner AA. Central nervous system perivascular cells are immunoregulatory cells that connect the CNS with the peripheral immune system. Glia 2001;36:156-64

Wilms H, Rosenstiel P, Sievers J, Deuschl G, Zecca L, Lucius
R. Activation of microglia by human neuromelanin is NF-kappaB dependent and involves p38 mitogen-activated protein kinase: implications for Parkinson's disease. Faseb J 2003;17:500-2

Wright SD, Ramos RA, Tobias PS, Ulevitch RJ, Mathison JC. CD14, a receptor for complexes of lipopolysaccharide (LPS) and LPS binding protein. Science 1990;249:1431-3

Wu DC, Jackson-Lewis V, Vila M, Tieu K, Teismann P, Vadseth C, Choi DK, Ischiropoulos H, Przedborski S. Blockade of microglial activation is neuroprotective in the 1-methyl-4-phenyl-1,2,3,6-tetrahydropyridine mouse model of Parkinson disease. J Neurosci 2002;22:1763-71

Yamada T, McGeer PL, McGeer EG. Lewy bodies in Parkinson's disease are recognized by antibodies to complement proteins. Acta Neuropathol (Berl) 1992;84:100-4

Yan SD, Chen X, Fu J, Chen M, Zhu H, Roher A, Slattery T, Zhao L, Nagashima M, Morser J, Migheli A, Nawroth P, Stern D, Schmidt AM. RAGE and amyloid-beta peptide neurotoxicity in Alzheimer's disease. Nature 1996;382:685-91

Zecca L, Pietra R, Goj C, Mecacci C, Radice D, Sabbioni E. Iron and other metals in neuromelanin, substantia nigra, and putamen of human brain. J Neurochem 1994;62:1097-101

Zhang W, Wang T, Pei Z, Miller DS, Wu X, Block ML, Wilson $B$, Zhou Y, Hong JS, Zhang J. Aggregated alpha-synuclein activates microglia: a process leading to disease progression in Parkinson's disease. Faseb J 2005;19:533-42 